following RA completion. Farmers who completed half-day training specified $40 \%$ more controls. Farmers who implemented the controls they specified had a significantly higher percentage of farms with satisfactory OSH standards (92.1\%) compared to those who did not implement controls (56.5\%). Conclusion The study concluded that completion of the RA in association with training led to more specification of controls. It also concluded that while the RA has positive utility among adopter farmers, more comprehensive approaches are needed to support its use among farmers challenged to implement OHS control measures.

\section{DEVELOPMENT OF HUMAN RESOURCES FOR THE PREVENTION OF NEGATIVE EFFECTS OF OVERWORK ON HEALTH IN JAPAN}

Yosuke Miyazaki*, Hisanori Hiro, Kazuaki Kawai, Hiroto Izumi, Yoshiyuki Shibata, Tomonori Igarashi, Kazunori Ikegami, Seichi Horie. University of Occupational and Environmental Health, Japan

\subsection{6/oemed-2018-ICOHabstracts.281}

Introduction Karoshi (death from overwork) has been a difficult challenge in Japanese society for a long time. In July 2015, the cabinet of Japan approved a guideline required by the Act on Promotion of Preventive Measures against Karoshi and other Overwork. In response to the guideline, the University of Occupational and Environmental Health, Japan (UOEH) launched a project to develop human resources to prevent harmful health effects from overwork. This report summarises the programmes for human resources development provided by UOEH

Methods The Centre for Stress-related Disease Control and Prevention (CSDC) was established at UOEH to perform development of human resources in April 2016. At first, the CSDC created a special training programme for 35 experienced occupational physicians who are certificated by the Japan Society for Occupational Health, to improve their understandings of health issues arising from overwork. Those physicians who completed this programme were appointed as on-site lecturers of UOEH. Then, the CSDC delivered various seminars together with the on-site lecturers, targeting occupational physicians, nurses, hygienists and human resource personnel around Japan to let them prevent and overcome the adverse health effects from overwork. Questionnaires were provided to the participants in the seminars for their improvement.

Results All except for one occupational physicians completed the special training programme in 2016. Regarding the seminars, the total number of participants by July 2017 was counted as 355. All together $69 \%$ of the participants responded to the questionnaires and $93.4 \%$ of the responders were satisfied with the seminars. Furthermore, $86.7 \%$ of them thought the skills and knowledge provided through the seminars were applicable to their work.

Conclusion The CSDC, an organisation at UOEH, was established to rise on-site lecturers and to deliver seminars with them for the prevention of the adverse health effects from overwork.

\section{6 \\ PHYSICAL EXERCISE DURING WORKING HOURS FOR EMPLOYEES AT A HOSPITAL LAUNDRY - A QUALITATIVE PROCESS EVALUATION}

${ }^{1} \mathrm{MB}$ Panduro*, ${ }^{2} \mathrm{LL}$ Andersen, ${ }^{1} \mathrm{~L}$ Brandt. ${ }^{1}$ Clinic of Occupational and Environmental Medicine Odense University Hospital, Denmark; ${ }^{2}$ National Research Centre for the Working Environment, Denmark

\subsection{6/oemed-2018-ICOHabstracts.282}

Introduction The present study is to provide an understanding of the motivational factors and barriers that influence compliance with physical exercise during working hours that are aimed at reducing musculoskeletal disorders, for employees at a hospital laundry.

Methods This study used a semideductive, thematic, and structured in-depth interview that was nested in an ongoing project with 140 laundry employees at a hospital laundry with 3 different geographic locations, that have been physical active at work since January 2015. The interviews was conducted 72 weeks within the main project among 22 informants with diverse field of laundry work, where the majority participated in the resistance band training at the workplace for $5 \mathrm{~min}$, three times per week. The following factors, organisational, implementational, and individual motives and barriers were explored.

Result The results indicates that there should be attention to the interaction between management, the employees and the aim of the intervention, since the main barrier for compliance in this study is internal working culture. The results emphasised a certain need of clear connexion between the management's intentions of the implementation of physical exercise at work and the actual implementation. There was also a strong correlation between the employee's motivation and participation in relation to the manager's participation at the daily physical exercise at the workplace. Additionally the results emphasise the importance of ensuring the cooperation among manager's, participants and colleagues in order to ensure compliance regarding the intervention.

Discussion Our recommendations from this study suggest a thorough pre-evaluation in order to analyse the organisational and implementation factors before the implementation of physical exercise at work.

\section{SUFFERING AT WORK AMONG MEDICAL STUDENTS: QUALITATIVE STUDY USING SEMI-STRUCTURED INTERVIEWS}

${ }^{1}$ AS Le Provost, ${ }^{2,3,4} \mathrm{R}$ Pougnet, ${ }^{5,6}$ J Pietri, ${ }^{7} \mathrm{~L}$ De Parscau, ${ }^{2,3} \mathrm{~B}$ Loddé, ${ }^{2,3} \mathrm{JD}$ Dewitte. ${ }^{1}$ Centre de Consultations de Pathologies Professionnelles, CHRU, Brest; ' $2 E A$ 4686, Ethique, Professionnalisme et Santé, Université de Bretagne Occidentale, Brest; ${ }^{3}$ Centre de Consultations de Pathologies Professionnelles, Médecine du Travail du Personnel Hospitalier, CHRU, Brest; ${ }^{4} E D$ 507SHS, Ecole doctorale Sciences Humaines et Sociales, Rennes; ${ }^{5}$ Anesthésie, Clinique du Grand Large, Brest; ${ }^{6} \mathrm{CCTV}$, CHRU, Brest; ${ }^{7}$ Service Pédiatrie et Génétique Médicale, CHRU, Brest

\subsection{6/oemed-2018-ICOHabstracts.283}

Introduction Suffering at work among health professionals is a hot topic. Medical students, doctors of tomorrow, are far from being spared. Prevalence of anxiety and mood disorders range from $20.3 \%$ to $69 \%$ for the former and from $12 \%$ to 
$30 \%$ for the latter. The purpose of this article was to determine these factors by qualitative research, according to medical students points of view.

Methods It was a qualitative study using semi-structured interviews. The analysis was done according to Grounded Theory.

Results 12 medical students were interviewed. They expressed difficulties at work and positive factors. Three major themes were identified in selective coding: occupational factors, 'study' factors and individual factors. All themes were both a source of well-being and ill-being according to the situations specified in the results.

Conclusion Studying medicine includes positive and negative aspects. Abandonment issues, lack of recognition and insufficient coaching emerge from our study. These results open lines of thought on the ways of improving formation of medical students.

\section{THE INFLUENCE OF OCCUPATIONAL MEDICINE PROGRAM IN MEDICAL STUDENTS' ATTITUDE TOWARDS THIS SPECIALTY}

Armand Rajnoveanu*, Razvan Ionut, Maria Barsan, Andreea Socaciu, Marilena Oarga. Iuliu Hatieganu University of Medicine and Pharmacy, Dept. of Occupational Medicine, ClujNapoca, Romania

\subsection{6/oemed-2018-ICOHabstracts.284}

Introduction Occupational medicine in Romania is not one of the first choices for residency training programmes and there are medical schools with no or just an optional educational program in this specialty for medical students. We tried to estimate the influence of such a program in changing students' attitude towards our specialty.

Methods We used the 18 items questionnaire developed by Smits and Verbeek and published in Occupational Medicine Journal in 2015, which was applied in its original form (English version) on 141 fourth-year medical students before and after their educational program in occupational medicine. Data was collected in a Microsoft Excel Datasheet and analysed using statistical functions (average, sum, standard deviation, ttest paired samples, and 0.05 statistical significance threshold was used). Items were collapsed in three scales according to the authors (a career in occupational medicine - 6 items, occupational medicine as an interesting specialty - 11 items and role and position of the occupational physician - 1 item). Results For the first scale the mean score before was 17.35 and 16.87 after the educational program (0.48 difference and $\mathrm{p}=0.082)$. The second scale had a mean score before of 42.97 points and 43.78 after ( 0.81 difference and $p=0.010)$, and the third scale, 3.39 before and 3.58 after (difference of 0.19 and $\mathrm{p}=0.048)$.

Discussion Results showed us scores which are comparable with the ones described in the original paper. In our research the educational program didn't reveal a positive effect in students attitude regarding choosing a career in occupational medicine (the score decreased but not statistical significant). A positive response was noticed in changing their attitude about occupational medicine as a specialty (higher score after and statistical significant) and also in the awareness of the necessity of independence of the occupational physician from the employer.

\section{5 \\ NATIONWIDE OCCUPATIONAL MEDICINE TRAINING PROGRAM IN THE FINNISH INSTITUTE OF OCCUPATIONAL HEALTH}

Jari H Stengård* ${ }^{*}$ Eva Helaskoski. Finnish Institute of Occupational Health, Helsinki, Finland

10.1136/oemed-2018-ICOHabstracts.285

Introduction Teaching of occupational medicine is an integral part of the training of occupational health specialists. This training takes place in Finnish Institute of Occupational Health Institute (FIOH) in Helsinki and its four regional offices. A challenge is that instructors in different regions have different skills and their resources are different. Here we present our new, nationwide occupational medicine training program, which has recently piloted and launched. It consists of six modules that correspond to the learning objectives given in university curricula. Each module includes lectures, workshops and self-study but also practical tasks, such as workplace visits, outpatient work and literature search. In teaching we use a web-based learning platform.

Methods The program was developed in collaboration with a selected group of trainees and all instructors in Helsinki and in all regional offices of FIOH. Feedback from instructors and trainees was collected by employing a web-based questionnaire and face-to-face discussions.

Results Feedback from instructors and trainees has been positive. The following things are considered as benefits of the new program:

- trainees receive same kind of training, regardless of locations where they specialise,

- they can view lectures later on video and

- they can discuss with other trainees and instructors in other areas, and

- instructors can take advantage of each other's material,

- we can employ modern pedagogic theories and teaching methods and

- instructors can more easily communicate with their trainees.

Discussion We had a need to reform and unify occupational medicine training at $\mathrm{FIOH}$. Participation of students and all regional instructors was central to the success of the program development. Our program has been well received by trainees and instructors. Web-based learning platform makes it possible for us to take advantage of instructors' different skills and to use new pedagogical theories and methods in our teaching

\section{GROUP EXPERIENTIAL INTERVENTION IN GREEK HEALTH PROFESSIONALS FOR THE CONFRONTATION OF MOBBING}

${ }^{1}$ Koinis Aristotelis, ${ }^{2}$ Velonakis Emmanouil, ${ }^{3}$ Tzavella Fotini, ${ }^{4}$ Tziaferi G Styliani. ${ }^{1}$ Clinical Psychologist, MSc, PhD(c), Psychiatric Sector, General Hospital of Argolida/Dep. of Nursing Laboratory of Integrated Health Care, University of Peloponnese Sparti, Greece; ${ }^{2}$ Professor of Public Health, Faculty of Health Sciences NKU Athens, Greece; ${ }^{3}$ Lecturer in Sociology of Health, University of Peloponnese, Sparta, Greece; ${ }^{4}$ Assistant Professor of Community Nursing, Dep. of Nursing Laboratory of Integrated Health Care, University of Peloponnese, Sparta, Greece

\subsection{6/oemed-2018-ICOHabstracts.286}

Introduction There are many ways to tackle with mobbing, with mainstream counselling and psychological support either 